\title{
Global Partial Response in Skin
}

National Cancer Institute

\section{Source}

National Cancer Institute. Global Partial Response in Skin. NCI Thesaurus. Code C159953.

50-99 percent clearance of skin disease from baseline without new tumors (T3) in patients with $\mathrm{T} 1, \mathrm{~T} 2$, or T 4 only skin disease. 